\title{
Impact of sequence choice on flow measurement by phase contrast in the ascending aorta: breath hold and non breath hold Michael A Bolen
}

\author{
Address: Cleveland Clinic, Cleveland, OH, USA \\ from I3th Annual SCMR Scientific Sessions \\ Phoenix, AZ, USA. 21-24 January 2010 \\ Published: 21 January 2010 \\ Journal of Cardiovascular Magnetic Resonance 20 I0, I2(Suppl I):PI4I doi:|0.I I86/I532-429X-I2-SI-PI4 I
}

This abstract is available from: http://jcmr-online.com/content/I2/SI/PI4I

(C) 2010 Bolen; licensee BioMed Central Ltd.

\section{Introduction}

Cardiac Magnetic Resonance (CMR) is well suited for cardiovascular flow assessment. CMR offers unlimited imaging planes, does not require a contrast agent, and is free of ionizing radiation. Additionally, phase contrast velocity mapping (PCVM) allows non invasive quantification of blood flow and velocity with good reproducibility.

Application of PCVM to the assessment of aortic flow is useful as part of a routine cardiac MRI functional assessment. PCVM can be performed as either a breath hold $(\mathrm{BH})$ or non breath hold (NBH) acquisition. Some authors have suggested that NBH represents the preferred approach to phase contrast flow assessment. The impact of CMR sequence choice on PCVM of aortic flow in a clinical setting is not known.

\section{Purpose}

To assess the impact of sequence selection, including BH and NBH approaches, in the clinical assessment of forward and regurgitant flow in the ascending aorta by PCVM.

\section{Methods}

55 consecutive patients ( 45 male, $51+/-19$ years) referred for clinical CMR of the thoracic aorta were included. Both $\mathrm{BH}$ and NBH (Table 1) sequences were performed at the sinotubular junction (STJ) and mid ascending aorta. (MA). 10 additional patients were evaluated at MA, with NBH and BH sequences performed 2 times each to assess for within sequence variation. Finally, in 10 patients 8 gallon water phantoms were imaged using identical imaging parameters as the clinical protocol to evaluate potential offset errors associated with each sequence.

\begin{abstract}
Results
Differences were observed between the two sequences (Table 2). Slightly greater forward volumes were observed using the NBH technique. There was overlap in variation noted between sequences for forward volume measurement when compared to within sequence variation, however the regurgitant volumes did not show similar overlap. Smaller within sequence variation was noted with NBH. The phantom assessment revealed slightly smaller offset errors with use of NBH sequence.
\end{abstract}

\section{Conclusion}

Differences exist between flow results obtained with BH and NBH sequences, and caution should be used when comparing results obtained using these two different approaches. Within sequence variability and phase offset values both showed a trend toward higher values with $\mathrm{BH}$ sequence, and represent areas of further inquiry to optimize accuracy of PCVM flow assessment. 
Table I: Scanning parameters

\begin{tabular}{lll}
\hline Parameter & BH & NBH \\
\hline Echo time TR/TE (ms) & $4.8 / 2.8$ & $6.9 / 4$ \\
Flip angle (degrees) & 12 & 30 \\
Bandwidth & 478 & 263 \\
Matrix size & $320 \times 300$ & $320 \times 260$ \\
Pixel size (mm) & $2.5 \times 2.62$ recon 1.25 & $1.7 \times 1.4$ recon 1.25 \\
Frames/cycle & 30 & 30 \\
NSA & 1 & 3 \\
SENSE factor & 2 & 1.5 \\
Typical acquistion window (s) & 16 & 150 \\
\hline
\end{tabular}

Table 2: Measured volumes (55 patients)

\begin{tabular}{llllll}
\hline Values/cardiac cycle & BH mean & NBH mean & Mean abs. difference, SD & Signed mean difference, SD & P \\
\hline Forward volume, STJ & $97.9 \mathrm{~mL}$ & $102.1 \mathrm{~mL}$ & $8.9 \mathrm{~mL}(8.0)$ & $-4.2 \mathrm{~mL}(\mathrm{II} .2)$ & $-1.8 \mathrm{~mL}(10.2)$ \\
Regurgitant volume, STJ & $10.7 \mathrm{~mL}$ & $12.5 \mathrm{~mL}$ & $4.8 \mathrm{~mL}(9.2)$ & $+.04(6.1)$ & -0004 \\
Regurgitant fraction, STJ & $10.6 \%$ & $10.6 \%$ & $3.9 \%(4.7)$ & $-2.8(7.5)$ & .18 \\
Forward volume, MA & $92.0 \mathrm{~mL}$ & $94.8 \mathrm{~mL}$ & $6.3 \mathrm{~mL}(4.9)$ & $+.4 \mathrm{~mL}(2.9)$ & .96 \\
Regurgitant volume, MA & $8.6 \mathrm{~mL}$ & $8.2 \mathrm{~mL}$ & $2.0 \mathrm{~mL}(2.0)$ & $+.9 \%(4.1)$ & .01 \\
Regurgitant fraction, MA & $9.0 \%$ & $8.0 \%$ & $2.6 \%(3.3)$ & .12
\end{tabular}

Publish with Bio Med Central and every scientist can read your work free of charge

"BioMed Central will be the most significant development for disseminating the results of biomedical research in our lifetime. "

Sir Paul Nurse, Cancer Research UK

Your research papers will be:

- available free of charge to the entire biomedical community

- peer reviewed and published immediately upon acceptance

- cited in PubMed and archived on PubMed Central

- yours - you keep the copyright 